\title{
A CON'TRIBUTION TO THE PATHOLOGY OF EPILEPSY. A REPORT OF TWO CASES IN WHICH A PORTION OF THE CORTEX WAS EXCISED AND EXAMINED.
}

BY JOSEPH COLLINS, M.D., NeW YORK.

\section{(ABSTRACT.)}

The writer first referred to the difficulty of determin. ing what the exact status of the value of trephining for epilepsy was at the present time, and pointed out the necessity of limiting the phrase operation for epilepsy to trephining, removal of the dura, and excision of the cortex. He believes that the indications for operation in epilepsy are very limited, but that such indications occur in Jacksonian epilepsy, and with extreme rarity in so-called idiopathic epilepsy. Operation is indicated in Jacksonian epilepsy when there are evidences of irritation of a circumscribed motor cortical area: it matters not what such irritation may be caused by. Operation is indicated in so.called idiopathic epilepsy when the convulsive attack begins with and is confined to the same localized spasm, and especially if such localized spasm be the only convulsive manifestation. The points to which particular attention were directed in the first case were the careful clinical study ; the exact location of the lesion; the early operation, the patient having had only two or three attacks, and the distinct pathological lesion.

The patient was a boy 20 years old, in which there was neither history of epilepsy nor of trauma. His first attack was on the 29 th of November, 1894 , and was a typical " haut mal" attack, preceded by twitching movements of the thumb and index finger. Two or three times that week he had some twitchings in the fingers not accompanied by loss of consciousness. When he came under observation, examination showed no defect of station or gait, exaggeration of the right knee-jerk. some ankle clonus of the right leg, and grip of right 
hand somewhat weaker than the left. Right triceps re flex livelier than the left. Sensibility of the right side bad. Sensibility of the entire body normal. No suggestive ocular conditions. Preliminary operation performed by Dr. Gerster consisted of removing the vault of the skull covering the cortical area for the right hand.

Second operation three days later. The cortical area for the right hand was cut out. The patient made a good recovery and was discharged from the hospital two weeks after the operation, and with the exception of some severe epileptical form of attacks shortly after the operation, the patient has been free from manifestations of epilepsy since that time, now one year. The paralysis of the right upper extremity which occurred shortly after the operation, has almost completely disappeared, and the patient has been able to earn his living as a clerk.

Since the operation he has been taking small doses of bromide of potash.

The important pathological findings in the pieces of cortical tissues removed, were:

I. Meningo-encephalitis. This seems to have been chronic in character. To this was added the acute exacerbation, which probably occurred in the interval between the second and first operation.

II. Marked obliteration in the blood vessels of the pia and cortex. This vascular change was associated with the formation of new capillaries which appeared to have undergone hyaline degeneration.

III. Slow degenerative changes in the ganglion cells. The neuroglia hyperplasia in the cortical areas, although distinctly demonstrable, was not very marked.

IV. Softened areas must have resulted from the obliteration of some of the blood vessels just at the junction of the gray matter with the white, where the blood supply is poor.

V. Replacement of this softened area by true neuroglia tissue. This was well demonstrated in the specimen which shows both areas and neuroglia tissue closely as. sociated together in such a way that surrounding each excision of softening there is an advancing zone of neuroglia tissue.

The second case was a married woman 30 years old, of good family and personal history, who had suffered for six years from convulsive affections, which she referred to as a cramp in her leg, and which later became 
associated with typical "haut mal" attacks. These attacks gradually became more frequent, until she had twenty marked attacks in the legs, and two "haut mal" attacks in twenty-four hours.

The cortical area in which the left leg centre is situated was outlined, and the corresponding opening made in the skull by Dr. B. F. Curtis. The dura was laid back, and the cortex excised. Two days later sections from the removed cortex showed the presence of a large number of hamorrhages scattered throughout the entire sec. tion, but particularly conspicuous in the deeper part of the cortex that is nearer the line of section.

The specimens prepared after the Nissl method, show distinct and striking changes in the cells of the large pyramids. In addition to the great scarcity of the cells, there are protoplasmic processes, are then shrunken and attenuated. They stain more deeply than normal cells, and refuse to differentiate.

Only a few of the large pyramidal cells met with present a normal appearance.

The speaker did not think it well to advance any opinion based on knowledge obtained from the study of these cases, as to pathology of so-called idiopathic epilepsy, as he was keenly alive to the liability of error in generalizing on individual cases. He would, however, emphasize the necessity of cortical excision in operations done for epilepsy, because these cases, as well as others recorded, such as Van Giesson's show, that distinct lesion was frequently demonstrable.

\section{DISCUSSION.}

Dr. M. A. STARk, in discussing the papers on epilepsy, said: Concerning operations in epilepsy I have had a number of patients operated upon and have tabulated them from my case books. There are 24 of them, of which 13 were reported in my "Brain Surgery." The cases there reported as cured, were reported too early.

In none of the 24 has there been a cure. Although in some cases the interval between the operation and the recurrence has been from one to three and a half years, yet in none of them has relief been permanent. I consider that the cases were operated upon long enough ago for us to arrive at some definite conclusion, as the first operation was done in October, 1889. These patients were carefully selected. I have never had a case of idiopathic epilepsy operated upon, nor any case in 
which there was a very long duration between the trauma and the fit. I have really taken most of the precautions that Dr. Sachs recommends. It is my firm conviction that these operations should not be done by general surgeons, but. only by a few men who have had a large experience and who have been fortunate enough to see a good many of these cases. I am sure, the surgeons present will coincide with me in this, as it is a very dangerous thing for us to recommend operations that will be done by surgeons of little experience in this field of surgery. It is really a specialty of surgery and I wish to enforce this particularly. All my operations have been done with great care and the cases have been carefully collected, but I have to report 24 operations for epilepsy without a cure. This is very discouraging, and I am very reluctant to - recommend operation any more. I now say to these patients that while something may be removed that may be of interest to the pathologist, we cannot promise much for the patient.

With regard to these operations, the excision of a cyst is very unsatisfactory. When the wall is removed the fluid reaccumulates. When the cysts are very large, as I have sometimes see11 them, the patients may die on the table during the evacuation of the cyst. In surface clots the result is also unsatisfactory. In one of my cases of hemiplegia with epilepsy in a child, the hemiplegia had persisted for three months. Dr. McCosh exposed a considerable area of the motor cor tex and after laying back the dura we discovered a clot lying upon the inner surface. This was scraped off and then a curette was passed under the dura, and the inside of the dura was curetted, removing a large clot. The child has since recovered partially from the hemiplegia, but there has been a recurrence of the epilepsy and the child is no better. Even in cases that are operated upon early, therefore, the results have not been good.

As for excising brain tissue, that I have done too, but even after the excision of scar tissue or of normal tissue there has been a recurrence of the attacks of epilepsy. The scar result. ing from the wound of the brain may act as an irritant. In some cases as a primary result there is a certain amount of paralysis, but this passes off. I do not think, however, that permanent cure of the epilepsy is to be expected from such incisions or exsections.

As to abscess of the brain, it has been my fortune to see 12 cases, of which all were operated upon. I have made the diagnosis of abscess in two other cases; but a thrombus was found in one after death, and general meningitis in the other. In one case the abscess was to have been operated upon at nine o'clock, but the patient died suddenly at seven, from a rupture of the abscess into the lateral ventricle.

In the 11 cases operated upon the abscess was found in each 
case either at the operation or at the autopsy. Of these patients three recovered. Some of these cases were seen with Dr. Knapp, some were seen at the New York Eye and Ear Infirmary with Dr. Gorham Bacon, and four were seen with Dr. McBurney. The majority of the cases occurred subsequent to ear disease. I cannot confirm some of the statements of McEwen regarding symptoms. If you have read his book you will think it possible to make a correct diagnosis in all cases. The temperature is not always low in abscess. There are cases of brain abscess that have irregular temperatures, varying between $98^{\circ}$ and $106^{\circ}$ twice a day. I have seen such a case and advised against operation, on the theory that the case was one of thrombosis with pyæmia, but it was operated on, the abscess was evacuated, and the patient is now perfectly well. You cannot rely upon a low temperature nor on a slow pulse rate as diagnostic symptoms of abscess.

One of the interesting symptoms of brain abscess subsequent to ear disease on the left side is aphasia. This is of the subcortical type of Wernicke.

Thus one patient presented the following symptoms: He had periect power to understand what was said to him and to read; and he had no word-deafness nor word-blindness, but the association between the thing seen and the word for it or between the object named and its appearance was impossible. When the object named was concealed from him, he could not recollect how it looked, nor could he name objects shown him. An abscess was found in the temporal lobe which divided the fibres joining the temporal and occipital regions, and thus destroyed the associations between visual and auditory memories though the memories themselves were intact. He recovered after evacuation of the abscess.

I saw a case of right unilateral epilepsy recently which had been operated upon and in which the symptoms pointed to a tumor in the left hemisphere, as the cause. The patient had epileptic convulsions with right unilateral paralysis, and an operation was done over the left hemisphere, but at the autopsy the tumor was found in the right hemisphere. There was perfectly good decussation of the motor fibres, in the medulla. Such a case is inexplicable.

As to the operation itself, I am convinced that trephining is less useful than the flap operation. I have not seen the saw used which has been shown by Dr. Gerster. The instruments that Dr. McBurney uses are a very fine gouge and a chisel. He has been particularly skillful with these operations upon the head, and particularly rapid. The last operation that he did for me with a fairly thick skull in an adult, was done in $141 / 2$ minutes while the previous one took 17 minutes. This is pretty rapid work, for I have seen it take 25 minutes to get through 
the skull with a trephine. The chisel that he prefers is a very fine one, which is very sharp and narrow, and I have yet to see any accident from this operation.

The diagnosis made by Dr. Thomas of his case was certainly very interesting, and in examining the patient I only confirmed his diagnosis. I should like to mention that $I$ have been able to confirm McEwen's statement as to the change in the percussion note on the skull over the tumor. Dr. Thomas noticed as I did that there was marked flatness over the region of the left second frontal convolution, and that the difference in the percussion note as contrasted with that of the opposite side was very marked.

As to the condition of exophthalmus, I can understand very well how this can be caused by brain tumor, even when the tumor is not behind the eye. Some light was thrown upon this as being due to displacement of the brain, by an autopsy in a case seen recently at the New York Hospital. A tumor of the superior parietal convolution caused so much pressure in the left bemisphere as to force the callosal convolution that lay just beneath the falx cerebri over to the other side. In this case we thought we had found a secondary tumor of the callosal gyrus at the autopsy, but when we came to dissect the brain, it was found that the pressure had been so great in the left hemisphere that it had pressed the hemisphere downward, and over to the right side beneath the falx. The tumor in the fronal lobe undoubtedly pressed the entire brain mass downward upon the cavernous sinus, and thus produced the exophthalmus.

Dr. W. W. KEEN, in discussing the papers on epilepsy, said: As to the surgical part of Dr. Thomas' case I will say a few words. The diagno is I consider was one of the most exact that I have ever had occasion to see, as the tumor was precisely at the point that had been indicated. I made an incision from just below the temporal ridge parallel around to the front; I then went back to the fissure of Rolando and then back again to the temporal fossa. So great was the intra-cranial pressure that the flap was raised nearly a centimetre above the general level of the skull. I have marked this skull where the fissures are seen and the piece of paper represents the flap. I employed a chisel and I think Dr. Thomas will agree with me that it did not take over fifteen minutes. In view of the slight exophthalmus there was some doubt as to the position of the tunior, i.e., whether it began at the base of the second frontal or on the orbital surface, and that was the reason that led me to make the incision along the forehead. I was particularly anxious to see if there was anything on the orbital surface. I nibbled away some of the bone, being careful to take small bites, so that if the sinus was opened I could plug it up with Horsley's wax, 
but it was not opened. I then lifted the frontal lobe and could see beyond the lesser wing of the sphenoid, and could get my finger in, but nothing abnormal was perceived. I then opened the dura parallel with the edge of the bone, and the moment this was done just at the point indicated, a large portion of the tumor protruded through lie ruptured cortex. After tying the vessels, to my great surprise, I found that I was able to shell out the tumor completely. I took three fingers and simply scooped it out. The tumor was absolutely delimited, and was entirely separate from the brain. During the process of enucleation I noticed considerable fluid escaped, and I expressed the opinion that probably the ventricle had been opened. On inspecting the bed of the tumor and removing the clot I could see the lateral ventricle widely opened. Whether I saw the middle of the ventricle or whether it was the posterior or the lateral horn, I am not quite sure, but the ventricle was widely open, more so than I liave ever seen. The question tben arose, now what shall I do with it? I was a little averse to packing with gauze, but I feared that probably not finding as ready a vent externally as it did into the ventricle the blood would ac. cumulate, pass into the third and even into the fourth with fatal results, and consequently I determined to pack it. I packed the anterior portion of from the bed of the tumor with a strip of gauze and left the end protruding from the opening. So far the result has been very satisfactory, as the patient was out of bed in two weeks.

I consider the prognosis fair or even good. Most of you will remember Durand's case, in which the tumor was even larger than this and in the same position and of the same character, and the patient was alive four years after the operation. I would call attention to the fact that as a result of so much injury to the brain by the tumor and the surgical interference, paralysis very frequently exists. The paper on this skull shows the size and shape of the tumor I removed, and if you will observe here, you will see that the tumor must have reached to the fissure of Rolando, involved the first frontal, the whole of the second frontal, and considerable of the third frontal, yet there was very little motor paralysis. There was nothing but a moderate paresis of the lower face and a moderate aphasia. After the mechanical interference, there was no additional paralysis, but there was a diminution in the apliasia. I have the tumor here and also a drawing, which may interest some of you. The tumor turned out to be a hard sarcoma and this encourages me in the prognosis.

I thought you might be interested in seeing the tumor which I removed in December, 1889 , from a patient who is today still doing well. It seems as though the removal of large tumors was less dangerous than that of small ones. If this be 
true, it is probably clue to the fact that in searching for smaller tumors, we are apt to inflict an amount of injury uprn the brain which is incompatible with rccovery.

A few words as to the papers on the results in epilepsy. During the ten years since modern brain surgery began, the advancenent has been very conspicuous and I am glad to say that, as a result we are able at the present tine to draw some reasonable conclusions. In my own cases of epilepsy I have reported but few of them, for the reason that I wanted to be able to draw some reasonable conclusions from them, conclusions only to bc reached after consielerable tine. I think it is incumbent upon all of us to collate after a tinne all of our cases and the final history of eacli. By this means we may learn the correct resilt. My own experience in this n1atter, although I have not collated it, has been a moderately large one, and I am rather between the position occupied by 1)r. Sachs and that occupied by I)r. Starr. I l11ust say that (although many of my cases have passed ont of $111 y$ olsarvation and miny have entirely recovered) I an1 not able at the prescnt time to report a single known case as cured. By cured, I n11ean that after a reasonable tinte has elapsed the paticnt has had no fits. I would not be willing to accept one year, and I would scarcely be willing to accept two years. I think that in all cases of epilepsy we should exact the same time limit that a surgeon does in the case of cancer. We regard those cases as cured at the end of three years. I believe that in epilepsy we should certainly say two years, and I am rather in favor of three. Occasionally, even at the end of three years, the patient may be no better, but I have seen many cases of great annelioration. I an not disposed to take quite so pessimistic a view as Dr. Starr and not quite so hopeful a view as I)rs. Saclis and Gerster. I believe it is worth while in most cases of Jacksonian, traumatic, and even local epilcpsy, to operate, and I think the results will be satisfactory in a sufficient number of cases to warrant this. If I, personally, had epilepsy, I would run the risk of any operation rather than go through life with such a frightful disease as this. I am sure there is not one in this roon who has not fonnd among parents an almost unanimons willingness to have the one chance in a thousand tried in preference to suffering. In idiopathic or essential epilepsy I would not operate.

I am especially glad that attention has been called by Dr. Saclis to the time limit as to the onset and the duration of the attacks, as this is certainly a very important point. The earlier after the injury that we arc able to operate the greater will be the probability of relief. In cases that have gone on for many years I have always refused to operate, but it is impossible to draw a hard and fast line. Where epilepsy has existed for six years or more, I should hesitate to do any operation whatever. 
It is encouraging to know that in the cases that have been related to.day, improvement, which liad been absent soon after operation, has been observed later, and this agrees with what I have already stated. We must have a certain time to reacl definite conclusions, and it will require at least twenty years experience before these mooted questions can be settled to the satisfaction of the profession.

I must express my gratification at the able papers that hase been read here to-day. The localized pathological changes are excellently given. I do not think we shall ever cure fifty per cent. of the cases, but we can bellefit a sufficient number to make it worth while to run the risk of trephining. 